\title{
Residential Segregation Based on Ethnicity (With Special Reference to
} Thimbirigasyaya DSD)

Nirojini.P ${ }^{1}$ and Wijerathne.K.B.P.C.A ${ }^{2}$

\section{Abstract}

A city can comprise of settlements with different ethnic backgrounds in a given geographical space. Ethnic groups can be separately located spatially but that does not imply that their quality of life is similar and facilities are equally distributed. This study thus conducted to identify the patterns of segregation of population according to their ethnicity and the factors behind the ethnically segregated neighbourhood in Thimbirigasyaya Divisional Secretariat Division (DSD), with the help of population data in 2017. This paper employed the Duncan and Duncan's (1955) method of Dissimilarity Index to calculate the Segregation Index of population by using Microsoft excel software. The levels of segregation are categorized in this study according toMassey \& Denton's (1988) method for Dissimilarity Index.The Geographical Information System (Arc map10.1) was employed to map out the Index of Segregation of twenty Grama Niladhari Divisions (GNDs) in Thimbirigasyaya DSD. Factors behind the segregation were identified by the questionnaire survey in selected GNDs. Results revealed that the patterns of segregation can vary in urban spaces. North-central and North-Eastern part of Thimbirigasyaya DSD received high Segregation Index value for Sinhalese with high socio economical levels. Tamils are moderately segregated in the South-western corner of the DSD. Muslims' segregation is relatively low in the DSD, but according to Grama Niladhari Divisions (GND) wise, Kuppiyawatta east and Dematagoda GNDs show the highest Muslim population. When different ethnically segregated neighbourhoods in DSD are compared, it is clear that there are several social and economic inequalities, which affect the minor groups comparably. Muslim neighbourhoods are located in underserved areas with fewer facilities and unclean environment with lower economic levels. Therefore, better solution to minimise these problems is to develop mixed ethnic neighbourhood in urban spaces in Sri Lanka.
${ }^{1,2}$ Department of Geography and Environmental Management, Sabaragamuwa University of Sri Lanka

11nironiji92@gmail.com 2anuradhawijerathne1990@ gmail.com

Keywords: Dissimilarity, Ethnicity, Geographical Information System, Segregation Index, Thimbirigasyaya DSD 


\section{INTRODUCTION}

Population Geography is one of the branches of geography. The purpose of Population Geography is the study of the relationships between various forms of human activities such as economic, social, and political activities with the phenomena of physical geography. It is concerned with the spatial and temporal analysis of population. It involves not only the magnitude of human population but also its different characteristics, growth and mobility (Ghosh, 1985). The spatial segregation and concentration of population groups is historically an old phenomena and they go back at least to 2000-1600 BC, when the city of Babylon was described having composed of distinct quarters (Kempen, 1998). All over the world, a large number of population live along the coastal belt because the location of industrial cities such as Washington (capital of USA), Tokyo (capital of Japan), and the connectivity of sea routes to the countries, and also social and economic benefits such as job education and high standard of living styles. In developing countries, the population density is very high and the segregation according to ethnicity is also diverse in capital cities, which are located in coastal regions.

The concept of ethnicity denotes a group of people who are separated from another group by their culture, religion, and race, in a particular area. Segregation is a primarily spatial phenomenon that often examines how specifically defined groups occupy a particular place. As a topic of this study, segregation is both controversial and complex in developing countries at the same time the ethnic segregation plays an important role in the development of any city in urban arena. Segregation has not equally distributed in some area while other place shows a low representation. Segregation has often seen to mark a failure of assimilation and a process that spatially victimizes certain minority groups. In many parts of the regions are tried to eliminate the ethnic segregation (Kaplan, 2014). According to Kaplan's idea, the ethnic segregation is one kind of inequality in any kind of society from the past to the contemporary world. The ethnic segregation exists in all over the world considerably in developed countries such as America, Canada; on the other hand in developing countries such as India, Sri Lanka. Ethnic segregations mostly influence on developing countries, especially on socio economic conditions of the people who have been ethnically segregated.

Ethnic population patterns may show the levels of ethnic residential segregation can be used to identify the social inequality and consequences in Thimbirigasyaya DSD. Ethnic diversity has costs and benefits. In one hand, diversity in skills, education, and endowments can enhance productivity by promoting innovation. On the other hand, diversity is often 
associated with poor and ethnically targeted policies, inefficient provision of public goods, and ethnic-based hatred and conflict (Alesina et al, 2014). Ethnicity plays a key role in how people perceive vulnerability and how people make use of ethnicity for livelihood strategies. This perpetuates a trend towards increased ethnic separation and thus contributes to exacerbate conflicts (Korf \& Silva, 2014). According to Korf \& Silva's idea, the ethnic segregation pattern may give some advantages but when concerning a completely multi-ethnic society, it might bring about some disadvantages. Strong ethnic separation between major and minority groups within the Thimbirigasyaya DSD may be a critical factor in the future of a country like Sri Lanka where ethnic unrest and conflict have been prevailed for over two decades. As Manawadu (2016) pointed out in Colombo city, the under-served settlement density has indicated the different social status of the two ethnic groups where Muslim population was highly concentrated. There were 2135 low developed settlements falls in southern pockets of Colombo city.

Income inequality may also consist of both positive and negative effects on the development. On the negative side, a higher degree of income inequality may lead to conflict and crime, prevent the poor from acquiring education and lead to expropriation and lofty taxation discouraging investment. One problem is that they may be insensitive to group proportions within specific neighborhoods. Segregation of ethnic groups can represent commonalities of its members and enhances the ingroup view that may be a disadvantageous position in relation to the rest of the population. Altogether, the result of same ethnic solidarity may generate the organization of some political actions. In brief, in-group cohesion or connectedness of ethnic communities found in contexts of high residential segregation can potentially promote political engagement (Skirmunt, n.d.). The study of ethnic segregation and integration play a critical role in determining the social and economic development of many developing nations. The main target of this study is to identify the levels of ethnic segregation and its possible consequences on the society in a particular area or a region.

\section{PROBLEM STATEMENT}

Thimbirigasyaya DS Division consists of a large population differentiated by various ethnic identities, religions, and cultures. The places where these populations are residing in the study are also different. This difference can be seen especially according to ethnic variation among the people. Instead of having mixed ethnic neighbourhood, the DSD is specifically comprised of the people segregated according to their ethnicity. At the same time when considering the facilities, social opportunities such as infrastructure facilities have not been equally 
distributed in the geographical space. In some ethnically segregated areas are comprised of a less number of facilities and low economic conditions whereas some other ethnic groups are having lots of facilities such as infrastructure, settlement and the kind. Furthermore, where they live may control their chance to develop in any field or economic conditions in a particular area. Therefore, it is important to investigate the patterns and factors of ethnic residential segregation in Thimibirigasyaya DS Division.

\section{LITERATURE REVIEW}

The geographical view of ethnic residential segregation

The word segregation usually considers the inner differentiations of a city or urban part. For instance, the spatial or geographical separation of any kind of ethnic group, or in another case spatially arranged divisions between housing and a work place. However, the term often used to refer to the disparate spatial distribution of neighbourhoods by diverse population groups; in other words, it can be described as residential segregation (Andersson.et al, 2003).

Andersson.et al, (2003) pointed out that in Sweden, the immigrants congestion make way to formation of ghettos because of the specific patterns of ethnic residential segregation of migrants. Mainly his research aimed to study the spatial distribution in the context of traditional society at the same time causes and effects of dynamic processes. In his research, he used respectively two models to obtain further understanding such as racialization model and migration model.

The report describes the extent of, and changes in, segregation over the 1980 to 2000 period. The report examines five dimensions of segregation proposed by Massey and Denton (1988). As follows: evenness dimension: dissimilarity index exposure dimension: isolation index concentration dimension: delta index centralization dimension: absolute centralization index clustering dimension: spatial proximity index. Key findings are the dissimilarity of Hispanics and Asians from other groups generally held steady or declined, but because most Hispanic and Asian groups are growing, interaction with Whites also have been declined (Iceland et .al, 2002). Blumenstock \& Fratamico (2013) have explained ethnic diversity, segregation, and fractionalization has long been thought to play a critical role in the socioeconomic structure and overall stability of many developing countries. While the results from their case study are preliminary, through this work they sought to build a deeper understanding of the key drivers of segregation, and thereby informing policy to foster integration across ethnic lines. Kaplan (2004) studied segregation is both controversial and complex. Segregation has often seen to 


\section{Original Article}

mark a failure of assimilation and a process that spatially victimizes certain minority groups. Eliminating segregation is a normative goal in many societies hoping to end the division of their urban areas based on race and ethnicity. Whatever causes or consequences of ethnic segregation, it has the potential of redefining the ethnic experience altogether.

\section{Ethnic segregation in Sri Lanka}

Manawadu (2016) revealed that from $20^{\text {th }}$ century the segregation of the population in Colombo city has increased based on their ethnicity, especially among two minority groups such as Tamil and Muslim population. For the study, he used the standard index of segregation as defined by Duncan and Duncan (1955) and cluster sampling method. This study revealed that Sinhalese have dominated the city except in a few wards where the Tamils and Moors are segregated.

Following is the formulae that Manawadu used to calculate segregation index

$I^{*}=\left\{\left(X_{i}-Z_{i}\right) / 2\right\} /(1-X / Z)$

IS-Index of Segregation

$\mathrm{X}$-The total of subgroup " $\mathrm{x}$ " in the city

$\mathrm{Z}$-Total population in the city

$\mathrm{X}_{\mathrm{i}-T}$-The percentage of the " $\mathrm{x}$ " population in the $\mathrm{i}^{\text {th }}$ tract

$\mathrm{Z}$-The percentage of the total population in the $\mathrm{i}^{\text {th }}$ tract
The intensity of segregation can be classified into four levels as follows:

When the IS lies between 10 and 19, there would be a tendency to be segregated.

The segregation is much common in urban and sub-urban areas, as the society ingested with many complicated ethnic and socioeconomic systems (Nawfhal, 1988). In the process of history, many people of different ethnic origins migrated to the city, transforming Kandy city into a typical multi-ethnic city. The index of dissimilarity Duncan \& Duncan, (1955) has used in this study. Finally, ethnic residential patterns in Kandy city are continued to change. The tendency to change is higher due to the urban planning and urban development projects were implemented. Thennakoon et. al. (2017) explained about the process and characteristics of social and ethnic segregation in Sri Lankan Muslim community. The Study revealed that the causes of segregation were their higher birth rate and weak economic status, which led to vertical segregation of Muslim community. Currently, Muslim community is limited to vertical ethnic segregation. In future marriage the segregation can expand to horizontal segregation as well.

\section{Factors of ethnic segregation}

According to Kaplan's idea, he mainly reported that reasons or factors behind the segregation of any ethnic group are 1) Factors related to socioeconomic 
position 2) factors related to threats of physical harm 3) factors related to preferences of ethnic group 4) factors related to outright discrimination. In the US, neighbourhoods are mostly distinguished based on class, so that poor are often likely to segregate according their class. Kalpan reported that increasing economic opportunities for Blacks in the US enable many Blacks enter into the middle class but at the same time a large number of poor blacks are still concentrated within the inner cities. According to his findings classes may serve or make separate members of group. Furthermore, professional blacks have been spatially separated from professional whites. Socio economic disparities can affect government policies and that can exacerbate segregation (Kalpan, 2004). The US housing policy from development of the housing loan corporation in the 1930 to the location of public housing in the 1950 and 1960 reinforced existing patterns of black segregation. Even today in Western European countries, the desire to provide social housing can inadvertently foster higher levels of segregation among some groups. In some cases, segregation works as a form of defence in reaction to threats of physical harm. The desire of dominant group behaviour highly isolates minority groups (Hanhorster, 2001). Especially new immigrants get settle down in city centre or outer core of city when housing competition enforce the people to move toward slums and shanties. Southern European cities are more likely to reside in selfconstructed slum housing in 34 peripheral rings. Poverty is another reason for the segregation in any city or region (Malheiros, 2002).

Anas, A. (2014) conducted a research about "Ethnic Segregation and Ghettos" for this study and he observed a bewildering variety of political and public responses to segregation in Brazil, Cyprus, Europe, India, Israel, South Africa and the United States. According to the history, cities have concentrated the ethnic segregation in particular areas. They identified differences between voluntary and involuntary ghettos and they understood them using agglomeration economies, positive and negative externalities, bid rent theory, land and labour markets. They show that sharply segregated urban land use patterns can be socially efficient or inefficient depending on the nature of preferences and the externalities. He mentioned that in the third world countries, ghettos are often informal squatter settlements in the outskirts of large cities because poor migrants from rural areas cannot find affordable formal urban housing. He revealed that ghetto is not just a slum but it can include any significant and contiguous ethnic concentration including an economically vibrant one. So that according to his idea any of the specific ethnic group segregation make harm in most of the situation, especially in economical level of the particular ethnic group in urban parts. 


\section{Original Article}

According to Mohite's idea, the impoverished settlers in particular area or region can be often attributed to a distinct ethnic origin. The largest slum of Asia has called as Dharavi, which covered approximately 427 acres and make connection between two major railways in Bombay North and south. The slum Dharavi is comprised of a range of population from one-half to one million (Sharma, 2000). As well as Katyal and Lengade in 2004 reported that the settlements in Dharavi are least or underserved settlements. The most slums have made out by using asbestos sheets, bamboo sticks, plastics, wooden planks, and old car tires and discarded canvas bags. For instance, he mentioned the chief occupations of the people are leatherworking, embroidering, and pickle making. The area where the people highly segregated by ethnically, land is swampy, lacking toilet and water supply. Although many ethnicities mix in Dharavi, 37\% of the population, the largest group, is Tamil-speaking (Mohite, 2003). Causes of ethnic segregation in contemporary cities can be varied. In the third world, people coming from rural area to the city are settled down in the outskirt of larger cities. It forms squatter settlements day by day by the poor migrants. The competition for the resources like land, educational and employment opportunities within a developing county occurring, where economic growth over the past several decades has been inconsistent or socio economic problems such as un employment, poverty, and environmental degradation have affected large section of the population, irrespective of their ethnic background (Silva, 2014).

\section{OBJECTIVES}

\section{Major objective}

To identify patterns and factors of segregation of the population according to their ethnicity in Thimbirigasyaya DSD.

\section{Specific objectives}

To calculate the Segregation Index according to ethnicity in Thimbirigasyaya DSD

To map calculated Segregation Index according to ethnicity in Thimbirigasyaya DSD

To identify the factors of ethnic segregation by different population groups in Thimbirigasyaya DSD

\section{METHODOLOGY}

For the study of ethnic segregation, 2017 population data were collected from 20 Grama Niladari Divisions in Thimbirigasyaya DSD. The most popular method of calculating Segregation Index, the Duncan and Duncan's (1955) has adopted to provide a numerical definition and Dissimilarity or Segregation Index to compute the Segregation Index of 20 GNDs with the help of Excel software package 2007. 


$$
\mathbf{I S}=\frac{[(\mathbf{X i}-\mathbf{t i}) / \mathbf{2}]}{[\mathbf{1}-(\mathbf{X} / \mathbf{T})]}
$$

$\mathrm{X} i=$ Percentage of total population of group $\mathrm{x}$ in spatial unit $\mathrm{i}$

$\mathrm{X}=$ Total population of group $\mathrm{x}$ in the city

ti=Percentage of total population in spatial unit i

$\mathrm{T}=$ Total population in the city

The intensity of segregation has been classified into three levels as follows

$\begin{array}{ll}0-30 & \text { Low segregation } \\ 30-60 & \text { Moderate Segregation } \\ 60-100 & \text { High Segregation }\end{array}$

\section{Primary data}

In this study, 100 questionnaires were filled, 58 questionnaires for Borella North GN Division, 28 in Pamankada West GN Division and 14 questionnaires were filled by Kuppiyawatta east GN Division area. Three Grama Niladari officers have been interviewed and collected information about social and economic problems in those GNDs.

The segregation of minority groups from the total population was determined based on Massey \& Denton's Categorization of the Index of Dissimilarity as follows. Segregation sensitivity: Massey \& Denton's Categorization of the Index of Dissimilarity.

According to the Index of Segregation (IS) results, three have recognized, as the GNDs with high population segregation area. Among those three GNDs, Borella North and Narahenpitta had the highest segregation index for Sinhala population with 79.9 and Pamankada West got 38.57 Segregation Index for Tamil population while 19.7 Segregation Index was recorded for Muslim population in Kuppiyawatta East. Approximately 3331 families live in Narahenpitta GN division, 3331 families in Pamankada West GN Division, and 2100 families in Kuppiyawatta East GN division. Simple random sampling method was employed to select sample population. The study aimed at 100 of samples population. Therefore, 58 were selected from Borella North, also 28from Pamankada West and 14 from Kuppiyawatta East were chosen. There are some other ethnic groups in small amount those were Indian Tamil, Malay, Burger, Sri Lankan Chetti, Sri Lankan Baratha and others (Sampathpethikada, 2017).

Secondary data were already collected from Thimbirigasyaya DSD (Sampathpethikada, 2017). Book which consisted of the number of population for each GND according to their ethnic group such as Sinhalese, Sri Lankan Tamil, Muslims, Indian Tamil, Malay, Burgher and other group. Furthermore, details about the ethnic segregation have been collected through the Books, previous research, related articles, and websites. 


\section{Original Article}
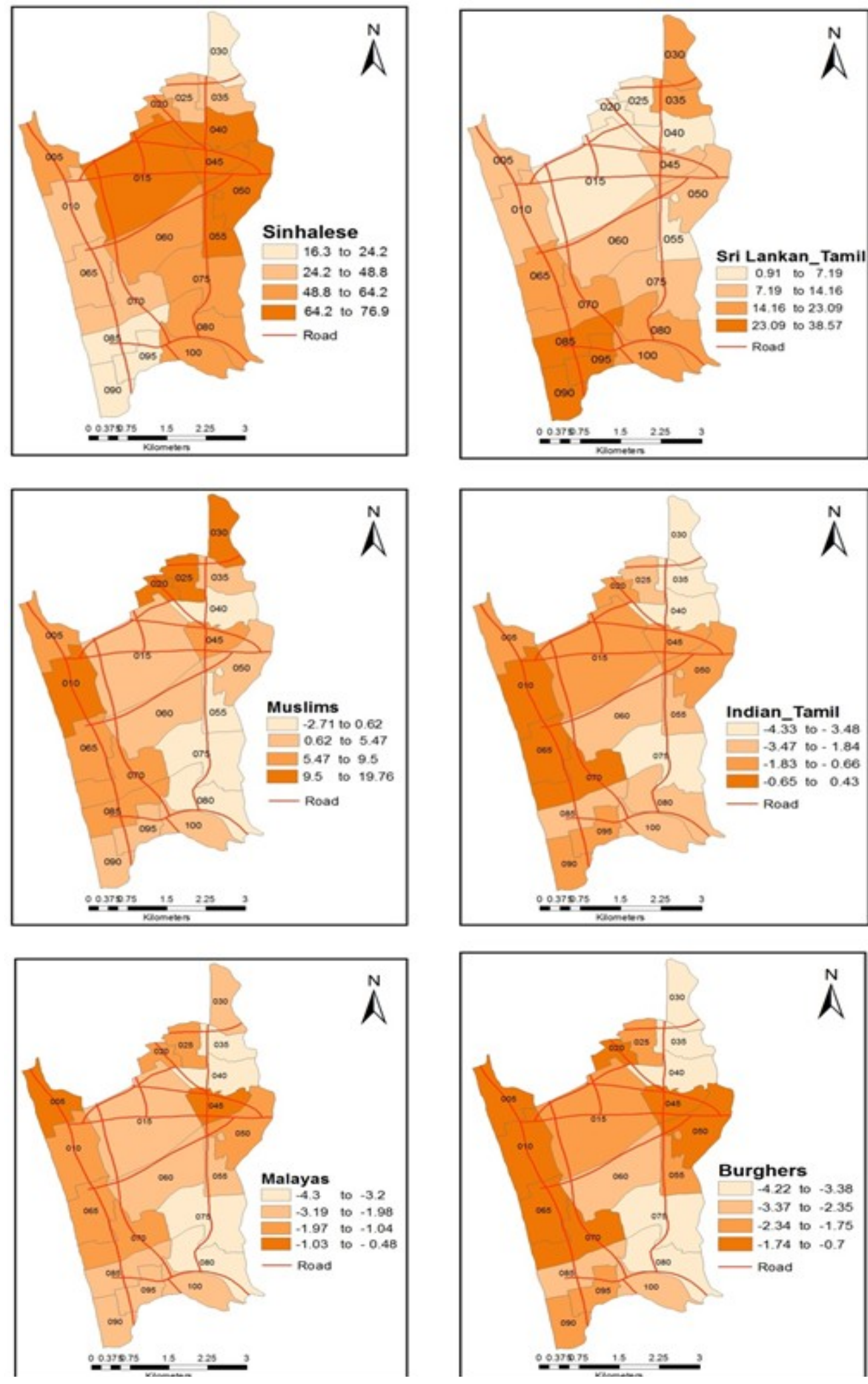

Figure 01: Spatial segregation of Ethnic Groups in Thimbirigasyaya DSD-2017 
Table 01: Segregation Index of Sinhala population in Thimirigasyaya DSD

\begin{tabular}{llcccc}
\hline $\begin{array}{l}\text { GND } \\
\text { code }\end{array}$ & GND_Name & Sinhalese & Total & IS & $\begin{array}{l}\text { Status according to } \\
\text { (Massey Denton's } \\
\text { categorization) }\end{array}$ \\
\hline 055 & Narahanpita & 8668 & 11194 & 76.93 & High \\
040 & Borella north & 17412 & 21372 & 76.68 & High \\
015 & Cinamon garden & 7,318 & 9914 & 73.67 & High \\
050 & Gothamipura & 4678 & 6498 & 73.26 & High \\
045 & Borella south & 3463 & 5137 & 69.02 & High \\
090 & Wellawatta south & 2825 & 10826 & 22.79 & Low \\
085 & Wellawatta north & 3278 & 14967 & 16.52 & Low \\
095 & Pamankada west & 2579 & 12451 & 16.38 & Low \\
065 & Milagiriya & 3246 & 7399 & 43.12 & Moderate \\
025 & Kuppiyawatta east & 4711 & 10577 & 42.41 & Moderate \\
010 & Bambalapitiya & 3066 & 7564 & 39.51 & Moderate \\
070 & Havelok town & 2901 & 7455 & 37.85 & Moderate \\
\hline
\end{tabular}

Source: Field survey,2019

Sinhalese are the largest and major ethnic group in Sri Lanka who are known to be low country and up country Sinhalese. There were 125,558 people in Thimbirigasyaya, constituting $57 \%$ of the total population in 2017. Their language is Sinhala, which is a member of IndoEuropean linguistic group.

The above figure 01 represents the segragation of Sinhala population who considered as the majority ethnic group of Thimbirigasyaya DSD.The geographic segregation of Sinhala population levels reveals that several high or moderate segregationthroughout the GNDs except Wellawatta south, Wellawatta north, and Pamankada west. High segregation values of sinhala population were represneted in the North East and North Central part of the DSD.The map shows the highest,moderate and lowest segregated area through the colour variations. The value of IS(Index of Segregation) in the highest segregated range between(64.2 - 76.9) of Sinhala population.Those areas were Narahenpita(79.93), Borella North(76.68), Cinamon Garden(73.67), as well as Gothamipura(73.26) and Borella South(69.02). Low Sinhala segregated areas are located in the south western part of the city such as Pamankada West(16.38),Wellawatta South(22.79), Wellawatta North(16.52) where the Tamil poulationis highly segrgated.At the same time the Sinhala population is moderately segreagted throughout other GNDs. For instance, Miliagiriya(43.12) Kuppiyawatta East(42.41), Bambalapitiya(39.51), Havelock Town(37.85), Kirulapana and Pamankada East. 
Table 01:Segreagtion index of Tamil population in Thimbirigasyaya DSD.

\begin{tabular}{llllll}
\hline $\begin{array}{l}\text { GND } \\
\text { code }\end{array}$ & GND name & Tamil & Total & Is & $\begin{array}{l}\text { Status according to } \\
\text { (Massey } \begin{array}{c}\text { Denton's } \\
\text { categorization) }\end{array}\end{array}$ \\
\hline 085 & Wellawatta north & 7604 & 14967 & 30.92 & Moderate \\
090 & Wellawatta south & 6200 & 10826 & 36.62 & Moderate \\
095 & Pamankada west & 7566 & 12451 & 38.57 & Moderate \\
030 & Dematagoda & 6377 & 18602 & 18.38 & Low \\
065 & Milagiriya & 2414 & 7399 & 20.50 & Low \\
070 & Havelok town & 2712 & 7455 & 23.09 & Low \\
010 & Bambalapitiya & 1642 & 7564 & 12.87 & Low \\
005 & Kollupitiya & 1557 & 6711 & 14.16 & Low \\
035 & Wanathamulla & 5057 & 17355 & 15.18 & Low \\
100 & Pamankada east & 3454 & 12389 & 15.75 & Low \\
080 & Kirulapana & 5538 & 17846 & 16.35 & Low \\
\hline
\end{tabular}

Source: Field survey,2019.

The people collectively known as Tamils, comprising 66,693 persons in Thimbirigasyaya DSD are approximately $28 \%$ of the total population in 2017. Tamil language is their mother tongue and it is one of the Dravidian languages. The Tamil population highly distributed in Northern Province of Sri Lanka.

The figure 01 shows the segregation of Sri Lankan Tamil population. Residential concentration of Tamil population in the study area reveals two parts, the first one is that the areas with high concentration of Tamils and the second one is evenly distributed areas. The map shows the moderate segregation of Tamil population in the South Western corner part of the DSD. Mainly these GNDs showa moderate segregation range from (23.09 to 38.57) such as Pamankada West (38.57),
Wellawatta South (36.62), Wellawatta North (30.92). The lowest segregation of Tamil population shows in Havelock Town with a segregation index of (23.09), Pamankada East (15.75), Kirullapanna (16.35), Wanathamulla (15.18). And the Tamil population is segregated in rest of the areas represent a Low level range: North (0.91), Kuppiyawatta West (3.11), Narahenpitta

Kuppiyawatta East (6.93), Cinamon Garden(7.19). Even though Tamil population is comprised of a small proportion when compare with the total population. The segregation of Tamil population show too low, whereas the Sinhala population is segregated highly as shown in Borella North, Kuppiyawatta West and Narahenpitta. 
Table02: Segregation of Muslim Population in Thimirigasyaya DSD

\begin{tabular}{llllll}
\hline $\begin{array}{l}\text { GND } \\
\text { Code }\end{array}$ & GND_Name & Muslims & Total & IS & $\begin{array}{l}\text { Status according to } \\
\text { (Massey } \begin{array}{c}\text { Denton's } \\
\text { categorization) }\end{array}\end{array}$ \\
\hline 025 & $\begin{array}{l}\text { Kuppiyawatta east } \\
\text { Kuppiyawatta }\end{array}$ & 4019 & 10577 & 19.76 & Low \\
020 & west & 2223 & 6954 & 17.11 & Low \\
010 & Bambalapitiya & 2121 & 7564 & 14.64 & Low \\
030 & Dematagoda & 5608 & 18602 & 13.15 & Low \\
085 & Wellawatta north & 3355 & 14967 & 9.50 & Low \\
070 & Havelok town & 1313 & 7455 & 8.53 & Low \\
005 & Kollupitiya & 1074 & 6711 & 7.77 & Low \\
045 & Borella south & 755 & 5137 & 7.39 & Low \\
065 & Milagiriya & 1146 & 7399 & 7.29 & Low \\
\hline
\end{tabular}

Source: Field survey,2019.

The third largest minority group in Sri Lanka are Muslims who makes up approximately15percentage of population $(35,965$ persons $)$ in Thimbirigasyaya DSD. Muslims possess their own worship sites and cultural social circles. Mainly there are three types of Muslims, Sri Lankan Moors, Indian Moors, and the Malays. They were migrated from Arab to Sri Lanka as traders between the eighth and fifteenth centuries and then they have adopted the Tamil language.

Figure 01 shows the segregation of Muslim population in Thimbirigasyaya DSD.According to the map, a higher number of Muslims are segreagted in North Eastern part with the range between(9.5 to 19.76) but according to the categorization segregation level, the Muslims segregation shows low. For example, in the GNDs of Kuppiyawatta east (19.76), Kuppiyawatta west (17.11), Bambalapitiya (14.64), Dematagoda
(13.15). In remaining parts, segregation of Muslim population are scattered throughout the Thimbirigasyaya DSD for example Cinnamon Garden (2.09), Pamankada west (4.65), Pamankada East (5.42). The low segregated areas areBorella North (-1.81), Kirulla (-2.71), Narahenpitta (0.43) Kirullapana(0.63).

Indian Tamils of Sri Lanka are Tamil people of Indian origin who known as up country or hill country Tamils. There were 3450 Indian Tamil population live throughout the city. They were carried by British people as tea plantation workers in the estate sector of upcountry of Sri Lanka during $19^{\text {th }}$ and $20^{\text {th }}$ centuries. Then they were settled down in Central, Uva, Sabargamuwa and Western provinces. Throughout the city, their segregation was respectively moderate.

The map 4.4 shows the segregation of Indian Tamil population throughout 


\section{Original Article}

the study area. The total population of Indian Tamils is 3450 persons in the DSD. The higher range of Segregation Index is (-0.65 to 0.43$)$, and mainly there are three GNDs those were Bambalapitiya (0.29), Milagiriya (0.43), Havelock Town (-0.08). Least segregated area ranges from $(-4.33$ to 3.48) those were Kirulla (-3.75), Wanathamulla (-3.48), Dematagoda (3.48), and Borella north (-4.33).

A least number of ethnic Malays reside in Sri Lanka as a minority population approximately 2042. They came to Sri Lanka as a second wave (1796-1948) from the Malay Peninsula. They spoke Malay language and their religion was Islamic. Malays mostly live in Kollupitiya Borella South, Kirulla, kirullapana, Borella North, Wanathamulla GNDs. Their ranges of segregation show below zero and it means that there was no segregation.

Burgers known as a small ethnic group in Sri Lanka. They descended from
Portuguese, Dutch, British and they developed relationships with native Sri Lankan women. Their religion was Christian.

According to the map 4.6 Burghers are live along the western part of the study area and in eastern side (they reside in two GNDs Gothamipura and Borella North). There segregation is low in Dematagoda, Wanathamulla, Borella North, Borella South, Kirulla, Kirullapana.

\section{FINDINGS}

Factors Affecting Ethnic Segregation in Thimbirigasyaya DSD

\section{Quality of education}

Education status is the basic factor in any community that shows the quality of life. People with higher education level can have better experiences, good physical and mental health as well as lower levels of disability and mortality rate(Reynolds \&Ross, 1998).

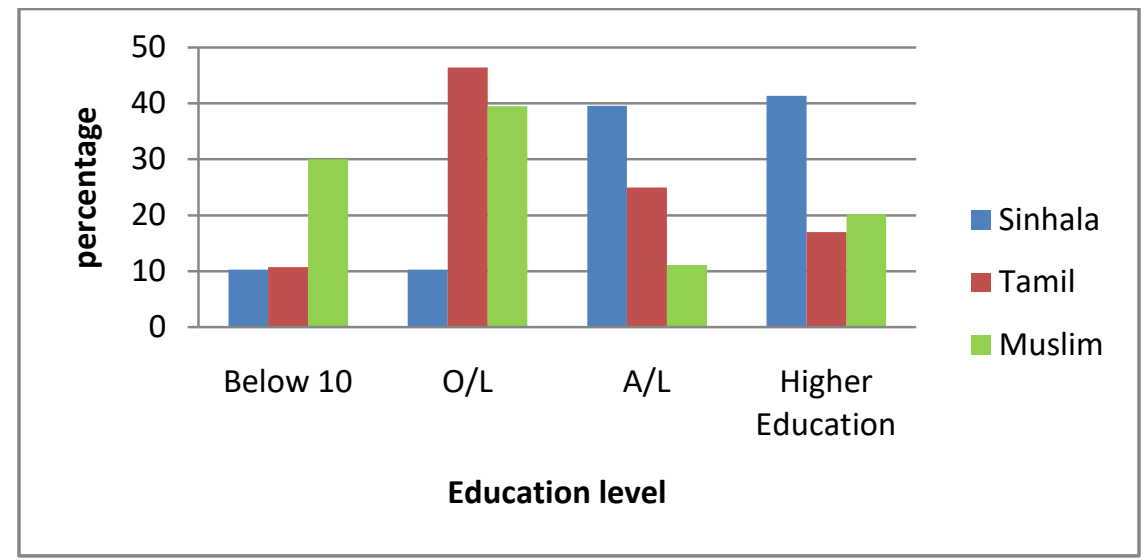

Figure 01: Education level of ethnic group in selected three GNDs.

Source: Field data, 2019.

Figure 01 shows the education level of the population by ethnic identity in
Borella North, Pamankada west and Kuppiyawatta East. The education 
attainment statuses of three ethnic groups are varied. People who studied below grade 10 were almost the same level for Sinhala and Tamil but the Muslim population proportion was high (30\%). The highest proportion of the people studied until O/L (ordinary level) $46.4 \%$ in Pamankada West. In Advanced Level (A/L) Sinhala population level was above $39 \%$ and Muslims (11.1\%) while the Tamil population proportion was $25 \%$. According to the proportion of three ethnic group's higher education level was not equal. It is varied by percentage as follow Sinhalese $(41.37 \%)$, Muslims (30.5\%), and Tamils (17\%).

Education level of Borella North and Kuppiyawatta eastis high because of the higher education facilities in Borella North and Kuppyawatta East GNDs. Most of the famous schools and institutions and most of the international schools were accumulated in north central part of the study area where the Sinhala and Muslim populations were segregated. For instance, famous schools like C.W.W. Kanangara Central School, Ananda College, Alhijra Muslim School, Khairiya Muslim Balika Maha Vidyalaya School and universities like University of Colombo in Cinamon Garden and many engineering and technical training institutes facilitates educations for above two groups. Altogether high level of education facilitates people to get a better educational status and motivate new comers to get settle down in that area. Educated neighborhoods often reflect their unwillingness to settle down with the least educated neighborhood. At the same time $30 \%$ of Muslim people studied below grade 10 live in the less developed area in Kuppiyawatta East.

As figure 1 show, lower level of Higher education was one of the major reasons for the Tamils segregation when compared to other ethnic groups. There were possible reasons behind lower education level of Tamil population. They came as immigrants during their young age and settled down in Pamankada West not obtained the same educational chances as the people born in other urban settings. At the same time Pamankada West GND has the less education Facilities. For instance, there is a Tamil school call as Ramakrishna Vidyalaya. Most of the Tamils settle down close by this school. Most of the Tamils in Pamankada West came as immigrants from North and Eastern provinces to the urban part of Colombo within 10 years period (2009 to 2019). 


\section{Original Article}

Income level

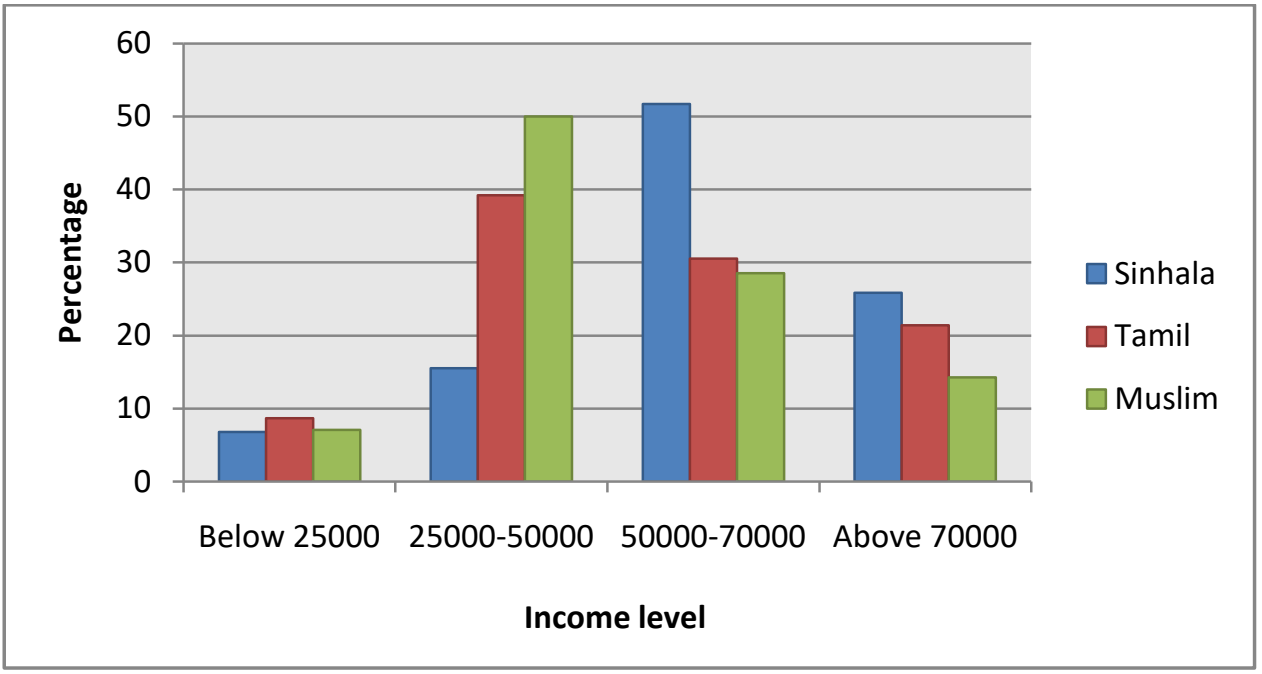

Figure 02: Income level of ethnic groups in three selected GNDs

Source: Field data, 2019.

Another possible factor that segregation deals with is the economic factor which measures the quality of economic level among ethnically concentrated neighborhoods. People with higher education or economic level are settled down in a specific place that reflects their position in the society.

Educational status and job opportunities influence the income level among people. The Figure 02 shows the income level of the population by ethnic groups. There are $10 \%$ of the population receive below $25,000.00$, under this salary scale most of them were trainees and workers in small shops. The salary scale of Sinhala population was low $(15.5 \%)$ in the range $25,000.00$ to $50,000.00 \mathrm{LKR}$ while high $(51.72 \%)$ in $50,000.00$ to $70,000.00$. Those who earn salaries above 70,000,00 among Sinhala population proportion was (27\%).
Through the questionnaire survey some information was gathered in Borella and according to those data, the major reason for their high income has been determined by their job status. Professionals, senior officers and managers etc. were accumulated in the urban space that stays in temporary residences $(72.41 \%)$ in Borella North. People who earn less than 25,000.00 in Borella North (6.8\%).The Tamil population's salary scale is high at $39 \%$ (25,000 between 50,000 LKR) and their income level is determined by their job status. For instance some are working as executive officers and managers while a large amount of them working as clerks or employees in private sectors. When considering the income level of Muslim population it was high (50\%) in the salary scale of (25000 to 50000) and $28.57 \%$ under the scale of (5000070000) their high participation in the 


\section{Original Article}

business activity. There were many opportunities for them to invest and develop their business and no any limitation for their salary scale. It further influences the segregation, and positive relation with the income level in their lives.

\section{Infrastructure}

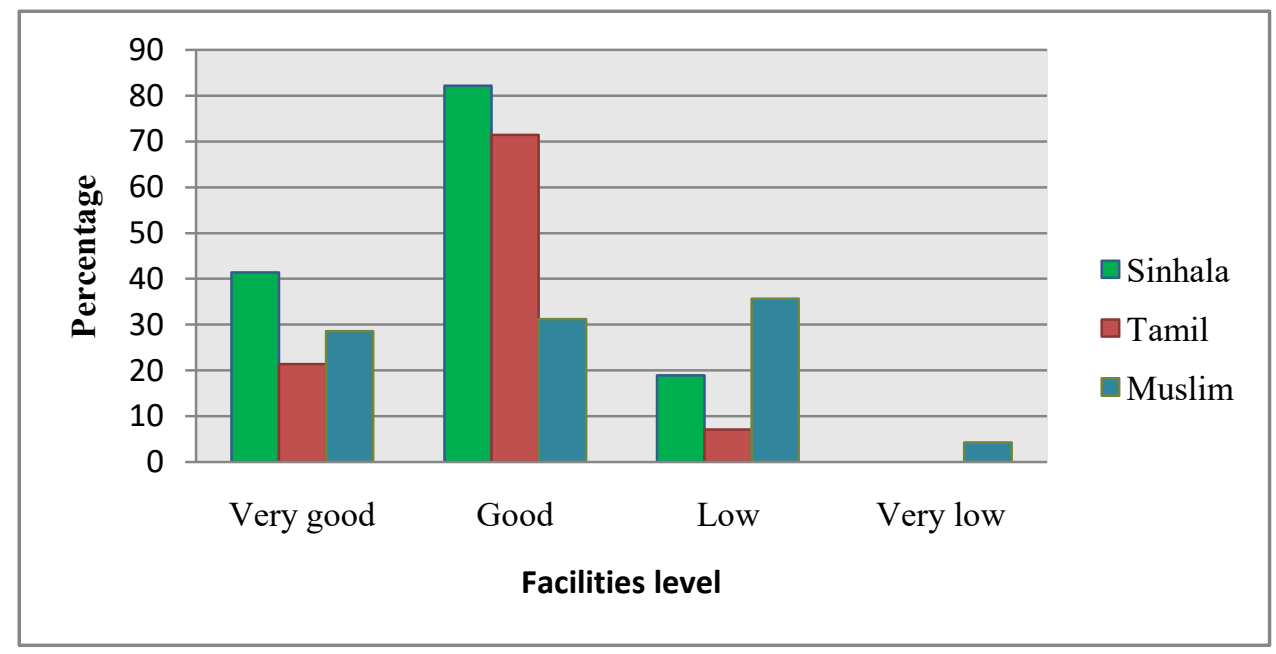

Figure 03: Transportation facilities in three ethnic segregated GNDs

Source: Field data, 2019.

Social services can increase the quality of life in any part of the urban area. Systematic and uneven spatial distribution of public services includes transportation, sanitation and health.

Figure03 represents the road network facilities in three GNDs where the ethnic groups were highly segregated. In all the GNDs the road network facilities were highly distributed because the day to day mobilization of population toward the city is high. The better transportation network is another reason for the ethnic segregation in a particular area. For instance the A2 main road (south end: Wellawaya and North end: Colombo fort) which goes through the Pamankada west GND is a possible reason why the Tamils are segregated along the road area and within the particular boundary. There were train services along the coastal area and it makes the transportation easier. The highest proportion of the people answered that their transportation was good: Sinhala (82.14\%), Tamils (71.42\%) and Muslims (31.24\%). The above chart concludes that the most of the population are satisfied with the transportation facilities. It is one of the possible reasons for their segregation near the roads and the railway stations. People who live in Kuppiyawatta East noted a low level of road access (35.71\%)

Overall, results of the analysis revealed that socio economic and 
infrastructural facilities are not equally distributed in the urban area. Moreover poverty, deprivation, race, and individual characteristics can impact the segregation while creating crimes and violence. There were no accurate data available for crime activities; it might be a disadvantage to prove emergence of violence activities in this region.

\section{CONCLUSIONS}

This study employed the Dissimilarity Index (Duncan and Duncan) method to identify the segregation pattern of three main ethnic groups such as Sinhalese the majority, and the minority Tamils and Muslims. This research mainly focused on their socioeconomic level as well as their quality of life and reasons behind it. The calculated Segregation Index for the each ethnic group in Thimbirigasyaya DSD shows the varied level of numerical value for every GND. There are statistically significant differences in the segregation level for urban setting in 2017. In common, for 2017, GNDs in the North and North East are the highly segregated areas in the Borella region. Details are as follows: South Western part is moderately segregated with a Tamil minority group. Sinhalese are the most segregated ethnic group in Thimbirigasyaya DSD; the majority ethnic group with a high Segregation Index value those of other ethnic groups. Tamils are the next most segregated group and Muslims were the least segregated ethnic minority group in Thimbirigasyaya DSD.

The segregation of Sinhala population can be seen in every corner of Thimbirigasyaya DSD but relatively high in the North Central and Eastern part of the study area. The segregation ranges between (76.9 to 48.8) in Narahenpitta, Borella North, Cinamon Garden, and Gothamipura GNDs. Most of the people live in Borella North are satisfied with their facilities because it is the hub of economically, industrially and socially developed region. However, there was less number of people not satisfied with their facilities who are earning below $30,000.00$ per month income within Borella North. For instance, there are underserved settlements in Lesley Ranagala Mawatta in Borella region. Most of the people work as labourers in private companies or construction sector so that their poor living status can influence segregation within this particular area.

The second largest segregated minority group is the Tamils. They are highly segregated in the southern part of the study area, namely Pamankada West, Wellawatta North and Wellawatta South. Social and economic ways determine the segregation pattern of Tamils in southern pocket of the city. Most of the people in Pamankada West have obtained a middle level education as they receive fewer opportunities for education in their new urban setting. Their job status can also define their 
accumulation in these areas as most of them are working inprivate sectors located in Kollupitiya, Bambalapittiya, Kirulla, and Kirrulapana GNDs. The south west corner of the study area is mostly concentrated with private sectors where the Tamils are highly segregated. These all factors influence high segregation of Tamils in Pamankada West. When considering the Tamil people's income scale, the highest proportion of the people receiving below 50,000.00LKR of income are working under this salary scale in private sector and all of them are living in flats of large building complexes. At the same time, people who receive above 50,000.00 LKR of income are segregated in a particular area in Pamankada west and they live in single well-constructed houses.

Infrastructural facilities in Tamil segregated area are mainly comprised of transportation facilities, health facilities, and environmental facilities. The transportation facilities are in good condition here. The distribution of health facilities are not equally distributed in every region where the Tamils are segregated and it is one the major constrains faced by the Tamils. There are a few numbers of dispensaries to treat patients. The demand and the price of the land are high in Colombo city. Therefore, other than buying a land and building a house, it would be easy to purchase a flat in a housing scheme. So this became a one reason for high segregation of Tamils in the above mentioned areas. The lane called
Arethusa in Pamankada West is having most of the low level settlements and this lane is always littered.

The segregation of Muslim population in Thimbirigasyaya DSD shows a less number. Their segregation is highly determined in North part of the study area close to the core of Colombo city. The education level of Muslims is high in Kuppiyawatta east. The reason for this is that they have access to Government, international and private schools around there residence. Muslims are mainly self-employers, means that in Kuppiyawatta East, majority of Muslim population are engaged in trade activities. Their trade activities are not limited only to Kuppiyawatta West, but also prevailed all around the Colombo region. Trading is the main activity motivates them to be stable in one place and develop their life standards. For instance in Kuppiyawatta and Dematagoda areas, most of the clothing and other shopping malls are developed because of high concentration of the Muslims. When considering the income level of the Muslims, high proportion of them is earning income between 25,000.00 LKR to 50,000.00 LKR, because they are self-employed. They have got long term business stability. The economic status of Muslims are comparably low than the other two ethnic groups. When considering the infrastructural facilities, transportation and health, the transportation facilities are much poor in Kuppiyawatta GND. There are 
many of the minor roads available, but fewer major roads in the edge of GN boundary and the train service is also not well satisfied. Another Muslim population lives in less developed areas like Devala Road and Silva lane in Kuppiyawatta East. In these regions the facilities are too low. For examples; the roads were constructed using stone blocks which reflect the low quality of road condition and the quality of settlements are also too low. And the surrounding environment is also very unpleasant.

Altogether, these three ethnic groups (Sinhala, Tamil and Muslim) do not consume the same facilities in Thimbirigasyaya DSD. Minority groups of Tamils and Muslims are suffering from these problems as they are segregated highly in small urban space. Especially the Muslim segregated areas show an unclean environment with garbage. According to results, ethnic segregation creates negative impacts on societies especially in the urban settings. Often minority groups are affected by the segregation and at the same time the solidarity of one ethnic group may create huge problems in the society. Especially, those ethnic groups who show social and economic backwardness than the major ethnic groups can lead to a suppressed mentality that will further motivate them to do any criminal activity against the major ethnic group. The best example for this is the bomb attack happened in Colombo in $21^{\text {st }}$ of Aril 2019. This was happened as a result of the solidarity of one particular ethnic group. So that, the segregation of one ethnic group can be dangerous to the security of the other ethnic groups in a country.

There are many unemployment conditions in the study area. When the literacy rate is low, it can lead to incapable people with fewer skills and furthermore this affect people negatively to have well paid occupations. The separation of minority groups from the major society determines their skills and mentality. When an individual grows up in a specific ethnic group that person can have less skills. In contrast, a person grown in a mixed ethnic neighborhood may have multi skills and that person can be adjustable to any of the environment. Furthermore, the behavior of main ethnic group might be a reason for high segregation of minor ethnic groups in a specific area. The major ethnic group is likely to give-up the areas when the percentage of minority is elevated, for instance; earlier Pamankada West GND was a region that the Sinhalese are segregated highly than the other ethnics. But within 20 years period the situation has changed a lot as Tamils started to segregate there. So that Sinhalese refused to live with this minor group and left Pamankada west. Now Tamils are highly segregated there.

Colombo is the economic hub of Sri Lanka where many individuals work together for a better future of the 
country. In the current situation, the populations who live in urban spaces ethnically separated, and it might create advantages to the same ethnic group, but over segregation of one particular ethnic group for a long period of time sometimes may cause some issues in the country.

\section{Recommendations}

According to the findings and the suggestions given by the community, there are some recommendations given below. It helps reduce the imbalance of facilities and discourage the segregation within the group. Urban planners should consider about the population during the new constructions and implement new urban plans to reduce disadvantages. Policy makers also implement new policies which reduce the segregation of same ethnic group in one place, for instance, the rental houses. And, providing awareness programs for the people about segregation and negative influences especially to the less educated people. Government should consider the young adults and their unemployment situation in least developed urban areas. Create the housing programs with mixed ethnic neighbourhood is also another recommendation. Central Environmental Authority (CEO) should consider the environmental quality of the GNDs because in some ethnically segregated neighbourhoods did not adopt a proper waste management system.

\section{References}

Alesina.A, \& Michalopoulos.S, and Papaioannou.E, (2014). Segregation and Collective Political Action In Urban England. Available at: http://nrs.harvard.edu/urn3:HUL.InstRepos:27759620(Accessed on January, 19, 2019)

Bluemenstock.J and Fratamico.L, (2013).Social And Ethnic Segregation, A Framework ForAnalyzing Segregation With LargeScale Spatial Network Data.

Duncan, O.D. and Duncan, B., 1955, “A Methodological Analysis of Segregation Indexes", American Sociological Review, 20: 210

217.https://inequality.stanford.edu/publi cations/media/details/methodologicalanalysis-segregation-indexes-0

Gamachchige.R.N, (2013).A Social Geographical Study of Segregation Patterns of Muslims in Maharagama DS Division. Available at: https://www.researchgate.net/publicatio n/320272600(Accessed on January 20, 2019)

Gosh, B. (1985).Fundamentals of Population Geography.Sterling Publisher.

Iceland, J., Weinberg, D. and Lauren, H. (2014). The Residential Segregation Of Detailed Hispanic And Asian Groups In The United States: 1980-2010. [online] Demographic-

research.org.Availableat:https://www.de mographic-

research.org/volumes/vol31/20/31-20.pdf [Accessed on 28 Mar. 2019].

Kaplan.D.H.(2014).Ethnic and Racial Segregation. Available at: http://www.oxfordbibliographies.com/v iew/document/obo-9780199874002/obo9780199874002-0133.xml. [Accessed on January 15, 2019].

Kempen, R. V. (1998). Ethnic Segregation in cities: new forms and explanations in dynamic world.Sagejournals.

Manawadu.M (2016).Processes Driving Ethnic Segregation In Cities: A Case Study Of The City Of Colombo, Sri Lanka. 
Available at:

https://www.researchgate.net/publicatio n/267857143_PROCESSES_DRIVING_E THNIC_SEGREGATION_IN_CITIES_A _CASE_STUDY_OF_THE_CITY_OF_CO LOMBO_SRI_LANKA . (Accessed on January 8, 2019)

Nawfhal, A.S.M., 1988, “The Spatial Perspective of Residential Patterns of Kandy City, Sri Lanka", Geographical Review of Japan, Vol. 61, No 02, pp.225247.

Thennakoon.T.M.S.P.K. \& Gamachchige.R .N. (2017).Social and Ethnic Segregation of Muslim Community InMatara District, Sri Lanka.Availableat: https://www.researchgate.net/publicatio n/316474099_Social_and_Ethnic_Segrega tion_of_Muslim_community_in_Matara _District_Sri_Lanka. [Accessed January on 9, 2019]. 